\title{
Skin Cancer Development in Solid Organ Transplant Recipients in Switzerland (Swiss Transplant Cohort Study)
}

\author{
Nadja Angela Stenz ${ }^{\mathrm{a}}$ Susanne Stampf ${ }^{\mathrm{b}}$ Andreas W. Arnold ${ }^{\mathrm{c}}$ \\ Antonio Cozzio $^{d}$ Michael Dickenmann ${ }^{e}$ Olivier Gaide ${ }^{f}$ Mirjam Harms $^{a}$ \\ Robert E. Hunger ${ }^{g}$ Emmanuel Laffitte ${ }^{h}$ Michael Mühlstädt ${ }^{h}$ Mirjam Nägeli ${ }^{a}$ \\ Günther F.L. Hofbauer ${ }^{\mathrm{a}}$ and the Swiss Transplant Cohort Study \\ a Department of Dermatology, University Hospital Zurich, Zurich, Switzerland; b Institute for Clinical Epidemiology \\ and Biostatistics, University Hospital Basel, Basel, Switzerland; ' Department of Dermatology, University Basel and \\ Dermatologie am Rhein, Basel, Switzerland; dDepartment of Dermatology, Kantonsspital St. Gallen, \\ St. Gallen, Switzerland; 'Division of Transplant Immunology and Nephrology, University Hospital Basel, \\ Basel, Switzerland; ' Department of Dermatology, University Hospital of Lausanne, Lausanne, Switzerland; \\ gDepartment of Dermatology, Inselspital, University Hospital Berne, Berne, Switzerland; hivision of Dermatology \\ and Venereology, Geneva University Hospitals, Geneva, Switzerland
}

\section{Keywords}

Basal cell carcinoma - Melanoma Keratinocyte carcinoma Organ transplant recipient · Organ transplantation · Skin cancer · Squamous cell carcinoma

\begin{abstract}
Importance: Skin cancer, in particular squamous cell carcinoma, is the most frequent malignancy among solid organ transplant recipients with a higher incidence compared to the general population. Objective: To determine the skin cancer incidence in organ transplant recipients in Switzerland and to assess the impact of immunosuppressants and other risk factors. Design: Prospective cohort study of solid organ transplant recipients in Switzerland enrolled in the Swiss Transplant Cohort Study from 2008 to 2013. Participants: 2,192 solid organ transplant recipients. Materials and Methods: Occurrence of first and subsequent squamous cell carcinoma, basal cell carcinoma, melanoma and other skin cancers after transplantation extracted from the Swiss Transplant Cohort Study database and validated by medical re-
\end{abstract}

karger@karger.com www.karger.com/drm

Karger ${ }^{\prime \prime} \div$

GOPEN ACCESS
(C) 2020 The Author(s)

Published by S. Karger AG, Basel

This is an Open Access article licensed under the Creative Commons Attribution-NonCommercial-4.0 International License (CC BY-NC) (http://www.karger.com/Services/OpenAccessLicense), applicable to the online version of the article only. Usage and distribution for commercial purposes requires written permission. cord review. Incidence rates were calculated for skin cancer overall and subgroups. The effect of risk factors on the occurrence of first skin cancer and recurrent skin cancer was calculated by the Cox proportional hazard model. Results: In 2,192 organ transplant recipients, 136 (6.2\%) developed 335 cases of skin cancer during a median follow-up of 32.4 months, with squamous cell carcinoma as the most frequent one. $79.4 \%$ of skin cancer patients were male. Risk factors for first and recurrent skin cancer were age at transplantation, male sex, skin cancer before transplantation and previous transplantation. For a first skin cancer, the number of immunosuppressive drugs was a risk factor as well. Conclusions and Relevance: Skin cancer following solid organ transplantation in Switzerland is greatly increased with risk factors: age at transplantation, male sex, skin cancer before transplantation, previous transplantation and number of immunosuppressive drugs.

(c) 2020 The Author(s)

Published by S. Karger AG, Basel

Trial Registration: the study is registered on Clinicaltrials.gov under the registration No. NCT02361229. 


\section{Introduction}

Skin cancer represents over one third of all cancer cases in Switzerland [1]. Basal cell carcinoma (BCC) is the most common cancer overall in Switzerland and most other countries $[2,3]$. Squamous cell carcinoma (SCC) is the second-most frequent keratinocyte cancer following BCC [4]. Most keratinocyte carcinoma in the general population is indolent with a low mortality rate but causes relevant morbidity $[2,4]$. In the setting of immunosuppression such as in organ transplant recipients (OTR), the incidence of keratinocyte cancers, in particular SCC, increases 65 - to 250 -fold compared to the general population, greatly impacting morbidity and mortality $[2,4-11]$.
Due to improvements in clinical management, advances in transplantation medicine and immunosuppressive medication, outcomes and survival after solid organ transplantation have improved over the last few years. This, however, leads to an increased incidence of cancers after solid organ transplantation $[12,13]$. The Swiss Transplant Cohort Study (STCS) is a prospective cohort study screening all candidates for solid organ transplantation since 2008 and finally enrolling them at transplantation [14]. The enrolment rate exceeds 95\% and thus reflects well the transplant recipient population in Switzerland [15]. Skin cancers are prospectively captured in the 4 categories of SCC, BCC, melanoma and other skin cancers and allow the association of these skin

- Prospective cohort study of transplant recipients in Switzerland within the STCS

- Between May 2008 and June 2013

Inclusion criteria:

- All male and female recipients of solid organs in Switzerland registered in the STCS database with given informed consent

Exclusion criteria:

- Patients who withdraw their informed consent

- Recipients of non-solid organs

- Skin cancer data were collected from the STCS database

- Cases of skin cancer were validated with the patients' health history and pathology reports

- First and subsequent skin cancers were counted

- Skin cancers were classified into the following groups: SCC, BCC, melanoma, intra-epidermal cancers and others

- Intra-epidermal skin cancers were excluded from statistical calculation

- Descriptive analysis was performed for patient's characteristics

- Skin cancer occurrence by types is presented by date and number of events

- Method of cumulative incidences was used to estimate the probability of skin cancer

- Risk factors for skin cancer were modelled using a traditional Cox proportional hazard model and an extended Cox proportional hazard model

Fig. 1. Flowchart of Materials and Methods. STCS, Swiss Transplant Cohort Study; SCC, squamous cell carcinoma; BCC, basal cell carcinoma.

Skin Cancer in Solid Organ Transplant Recipients in Switzerland 


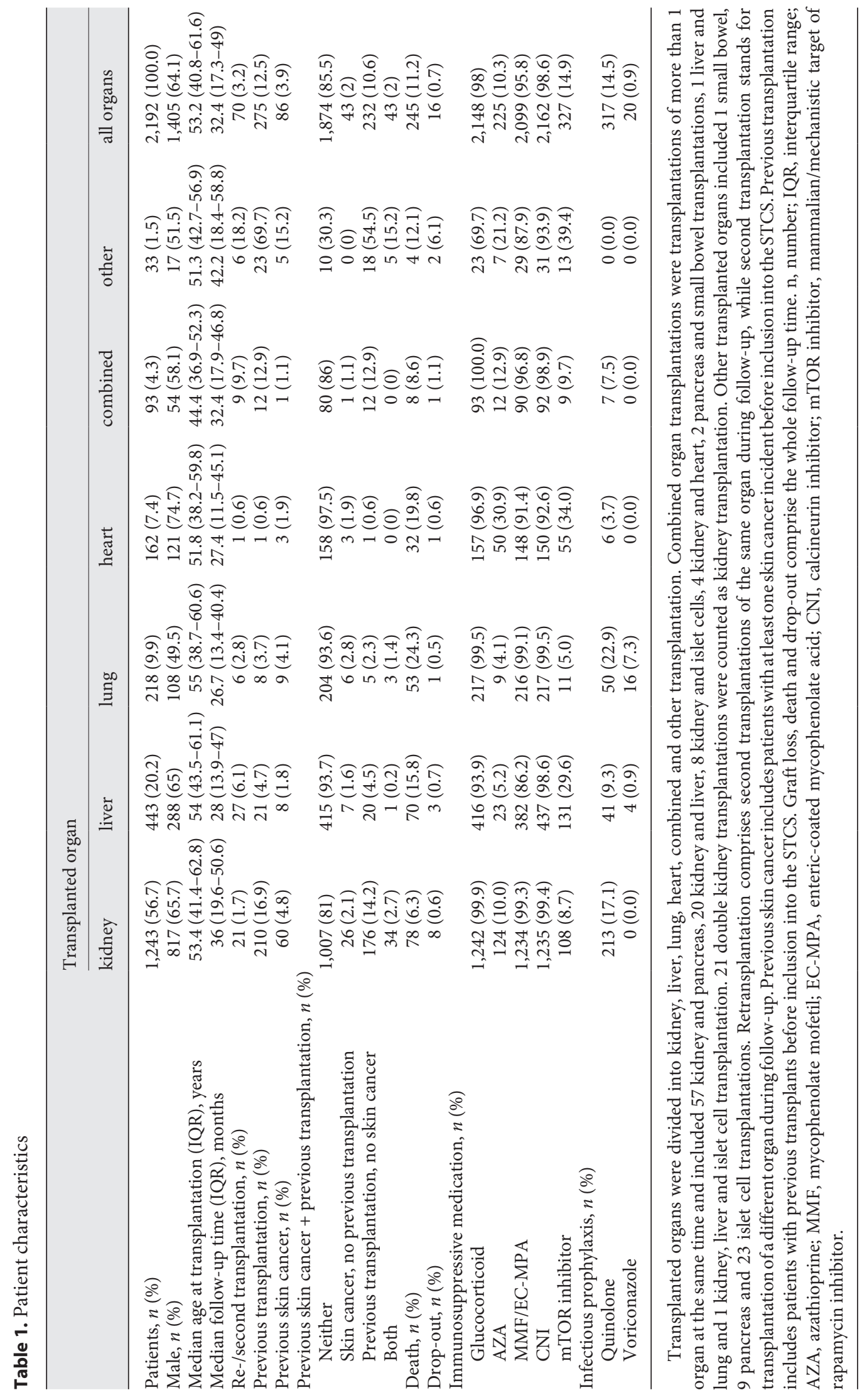


Table 2. Skin cancer cumulative incidence

\begin{tabular}{|c|c|c|c|c|c|c|c|}
\hline & \multicolumn{7}{|c|}{ Transplanted organ } \\
\hline Male & $76(82.6)$ & $11(73.3)$ & $9(64.3)$ & $5(83.3)$ & $2(66.7)$ & $5(83.3)$ & $108(79.4)$ \\
\hline SCC & $52(4.2)$ & $9(2.0)$ & $12(5.5)$ & $2(1.2)$ & $1(1.1)$ & $3(9.1)$ & $79(3.6)$ \\
\hline Male & $42(80.8)$ & $8(88.9)$ & $8(66.7)$ & $1(50.0)$ & $1(100.0)$ & $2(66.7)$ & $62(78.5)$ \\
\hline Melanoma & $3(0.2)$ & $1(0.2)$ & $2(0.9)$ & $0(0.0)$ & $0(0.0)$ & $0(0.0)$ & $6(0.3)$ \\
\hline Male & $3(100.0)$ & $1(100.0)$ & $2(100.0)$ & $0(0.0)$ & $0(0.0)$ & $0(0.0)$ & $6(100.0)$ \\
\hline Other & $1(0.1)$ & $2(0.5)$ & $2(0.9)$ & $0(0.0)$ & $0(0.0)$ & $0(0.0)$ & $5(0.2)$ \\
\hline Male & $1(100.0)$ & $1(50.0)$ & $2(100.0)$ & $0(0.0)$ & $0(0.0)$ & $0(0.0)$ & $4(80.0)$ \\
\hline $\begin{array}{l}\text { Median time to first skin cancer } \\
\text { (IQR), months }\end{array}$ & $13.9(8.4-22.7)$ & $14.2(8.9-22)$ & $15.6(6.5-19.5)$ & $15.2(12.5-22.5)$ & $11.9(7.4-17.3)$ & $18.2(3.9-36.8)$ & $14(8.4-22.7)$ \\
\hline
\end{tabular}

Skin cancer cases were divided into 4 groups: squamous cell carcinoma (SCC), basal cell carcinoma (BCC), melanoma and other. Other includes dermal sarcoma, sarcoma not otherwise specified, sebaceous gland carcinoma, Kaposi sarcoma and atypical lymphocytic proliferation of T-cell type. The number and percentage of all skin cancers and the different groups of skin cancer were calculated, as well as the number and percentage of male patients with skin cancer. Combined organ transplantations were transplantations of more than one organ at the same time and included 57 kidney and pancreas, 20 kidney and liver, 8 kidney and islet cells, 4 kidney and heart, 2 pancreas and small bowel transplantations, 1 liver and lung and 1 kidney, liver and islet cell transplantation. 21 double kidney transplantations were counted as kidney transplantation. Other transplanted organs included 1 small bowel, 9 pancreas and 23 islet cells transplantations. IQR, interquartile range.

cancer events with a large data pool on the individuals affected [14].

The present study aims to report the incidence of skin cancer overall and by cancer type within the STCS in the years 2008-2013. We present descriptive statistics for these skin cancers and report associated risk factors based on the high granularity of data captured in the STCS.

\section{Materials and Methods}

For further details, see the online supplementary material (see www.karger.com/doi/10.1159/000510685) (Fig. 1) [14, 16-18].

\section{Results}

Between May 2008 and June 2013, 2,192 patients with solid organ transplantation were included in our report. The median follow-up time was 32.4 months. Most of the patients $(56.7 \%)$ were kidney transplant recipients, followed by liver, lung, heart, combined (i.e., kidney and pancreas) and other (i.e., pancreas, small bowel) transplant recipients. The median age at transplantation was 53.3 years, while $64.1 \%$ of the OTR were male. During follow-up $98 \%$ of the patients received glucocorticoids at least once, 10.3\% azathioprine (AZA), 95.8\% mycophenolate mofetil, $98.6 \%$ a calcineurin inhibitor and $14.9 \%$ a mammalian target of rapamycin (mTOR) inhibitor. 317 (14.5\%) OTR were put on quinolones and $20(0.9 \%)$ on voriconazole during our follow-up time. Full details are provided in Table 1.

As shown in Table 2 in detail, a total of 136 patients developed 335 cases of skin cancer during follow-up. 79 patients developed SCC, 77 BCC, 6 melanoma and 5 other skin malignancies (dermal sarcoma, sarcoma not otherwise specified, sebaceous gland carcinoma, Kaposi sarcoma, atypically lymphocytic proliferation T-cell type). The cumulative incidence reached $6.2 \%$ for any skin cancer, 3.6\% for SCC and 3.5\% for BCC. $79.4 \%$ of the OTR with skin malignancy were male. 186 of these 335 skin cancer cases were SCC, 137 BCC, 7 melanoma and 5 other skin malignancies. This results in an SCC-to-BCC ratio of 1.4:1. The median time to first skin cancer after transplantation was 14 months (Table 3 ).

Figure 2 shows the probability of incident skin cancer during follow-up. With time after transplantation, the probability of SCC and BCC increases while the number of patients at risk decreases over time. Figure 3 shows the distribution of skin cancer after transplantation itemized for each skin cancer type. Each OTR with skin cancer is represented by a horizontal line. In Figure $4 a-c$ skin can- 
Table 3. Skin cancer events

\begin{tabular}{|c|c|c|c|c|c|c|c|}
\hline & \multicolumn{7}{|c|}{ Transplanted organ } \\
\hline & kidney & liver & lung & heart & combined & other & all organs \\
\hline Total number of skin cancer events, $n(\%)$ & $233(69.5)$ & $46(13.7)$ & $32(9.6)$ & $7(2.1)$ & $4(1.2)$ & $13(3.9)$ & $335(100.0)$ \\
\hline Male, n (\%) & $211(90.6)$ & $42(91.3)$ & $27(84.4)$ & $6(85.7)$ & $3(75.0)$ & $12(92.3)$ & $301(89.9)$ \\
\hline Total number of SCC events, $n(\%)$ & $128(68.8)$ & $23(12.3)$ & $21(11.3)$ & $2(1.1)$ & $2(1.1)$ & $10(5.4)$ & $186(100.0)$ \\
\hline Male, $\mathrm{n}(\%)$ & $116(90.6)$ & $22(95.7)$ & $17(81.0)$ & $1(50.0)$ & $2(100.0)$ & $9(90.0)$ & $167(89.8)$ \\
\hline Total number of BCC events, $n(\%)$ & $101(73.7)$ & $19(13.9)$ & $7(5.1)$ & $5(3.6)$ & $2(1.5)$ & $3(2.2)$ & $137(100.0)$ \\
\hline Male, $\mathrm{n}(\%)$ & $91(90.1)$ & $17(89.5)$ & $6(85.7)$ & $5(100.0)$ & $1(50.0)$ & $3(100.0)$ & $123(89.8)$ \\
\hline Total number of melanoma events, $n(\%)$ & $3(42.8)$ & $2(28.6)$ & $2(28.6)$ & $0(0.0)$ & $0(0.0)$ & $0(0.0)$ & $7(100.0)$ \\
\hline Male, n (\%) & $3(100.0)$ & $2(100.0)$ & $2(100.0)$ & $0(0.0)$ & $0(0.0)$ & $0(0.0)$ & $7(100.0)$ \\
\hline Total number of other events, $n(\%)$ & $1(20.0)$ & $2(40.0)$ & $2(40.0)$ & $0(0.0)$ & $0(0.0)$ & $0(0.0)$ & $5(100.0)$ \\
\hline Male, n (\%) & $1(100.0)$ & $1(50.0)$ & $0(0.0)$ & $0(0.0)$ & $0(0.0)$ & $0(0.0)$ & $4(80.0)$ \\
\hline
\end{tabular}

Total number of skin cancer events during follow-up by transplanted organ and different skin cancer types. $n$, number; SCC, squamous cell carcinoma; BCC, basal cell number.

Table 4. Risk factors for first skin cancer overall

\begin{tabular}{llrr}
\hline Risk factor & Reference & HR $(95 \%$ CI $)$ & $p$ value \\
\hline Age at transplantation & - & $1.059(1.04-1.079)$ & $<0.001$ \\
Male sex & female sex & $2.105(1.36-3.259)$ & 0.001 \\
Previous skin cancer & no previous skin cancer & $5.3(3.446-8.152)$ & $<0.001$ \\
Previous transplantation & no previous transplantation & $2.211(1.505-3.248)$ & $<0.001$ \\
Number of immunosuppressive drugs & - & $1.332(1.022-1.736)$ & 0.034 \\
\hline
\end{tabular}

The risk factors for first skin cancer were calculated using multivariate analysis. -, lack of reference; HR, hazard ratio; 95\% CI, 95\% confidence interval; see also Figure 3, legend text.

Table 5. Risk factors for recurrent skin cancer

\begin{tabular}{|c|c|c|c|}
\hline Risk factor & Reference & $\mathrm{HR}(95 \% \mathrm{CI})$ & $p$ value \\
\hline Age at transplantation ( $<2$ years of transplant) & - & $1.036(1.008-1.064)$ & 0.01 \\
\hline Age at transplantation ( $>2$ years of transplant) & - & $1.061(1.029-1.094)$ & $<0.001$ \\
\hline Male sex & female sex & $3.535(2.234-5.595)$ & $<0.001$ \\
\hline Previous skin cancer ( $<2$ years of transplant) & no previous skin cancer & $9.413(5.589-15.854)$ & $<0.001$ \\
\hline Previous skin cancer ( $>2$ years of transplant) & no previous skin cancer & $3.993(1.565-10.189)$ & 0.004 \\
\hline Previous transplantation ( $<2$ years of transplant $)$ & no previous transplantation & $2.576(1.657-4.003)$ & $<0.001$ \\
\hline Previous transplantation ( $>2$ years of transplant) & no previous transplantation & $1.634(0.732-3.648)$ & 0.231 \\
\hline Number of immunosuppressive drugs & - & $1.160(0.782-1.72)$ & 0.46 \\
\hline
\end{tabular}

The risk factors for recurrent skin cancer were calculated using multivariate analysis. -, lack of reference; HR, hazard ratio; 95\% CI, $95 \%$ confidence interval.

cer cases per patient, classified into any skin cancer, SCC and BCC, are illustrated. The majority of patients suffered 1 or 2 skin cancer cases, but there is a noticeable minority with a large number of tumours, especially SCC.
Multivariate analysis showed age at transplantation, male sex, skin cancer before inclusion into the STCS, previous transplantation and number of immunosuppressive drugs as risk factors for the development of a first 
Fig. 2. Probability of incident skin cancer. Probability of incident skin cancer is displayed for squamous cell carcinoma (SCC), basal cell carcinoma (BCC), melanoma and other cancers over time and over number of patients at risk. "Other" includes dermal sarcoma, sarcoma not otherwise specified, sebaceous gland carcinoma, Kaposi sarcoma and atypical lymphocytic proliferation of T-cell type.

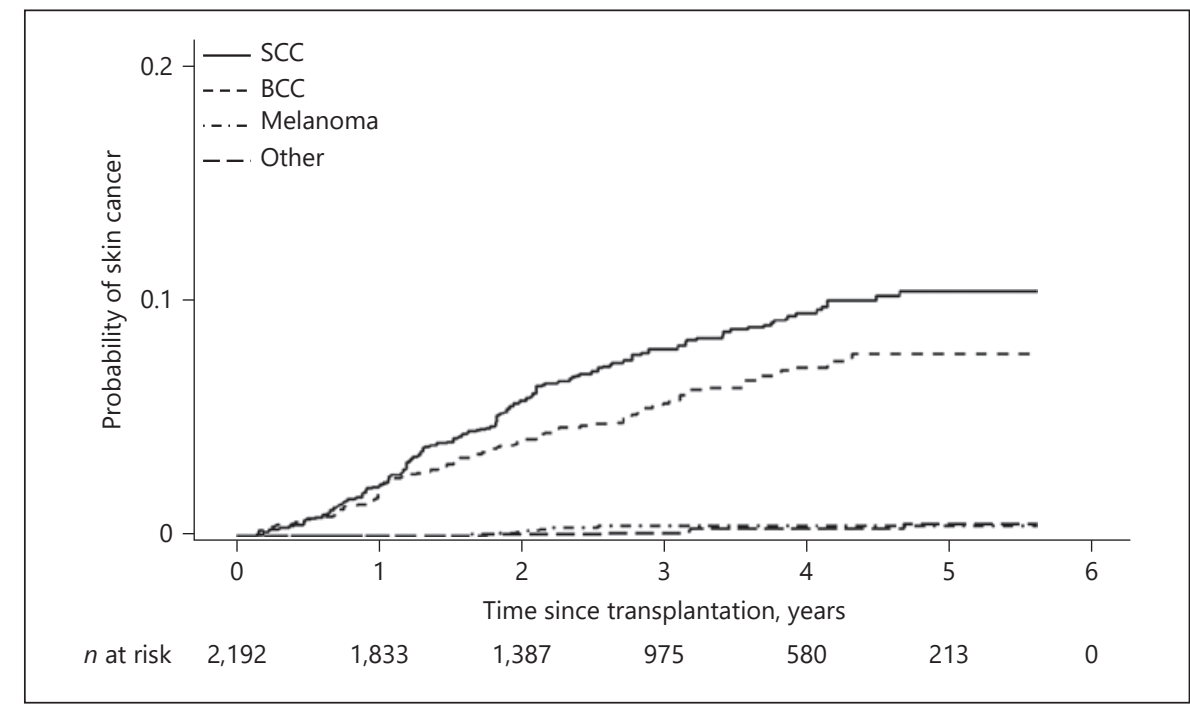

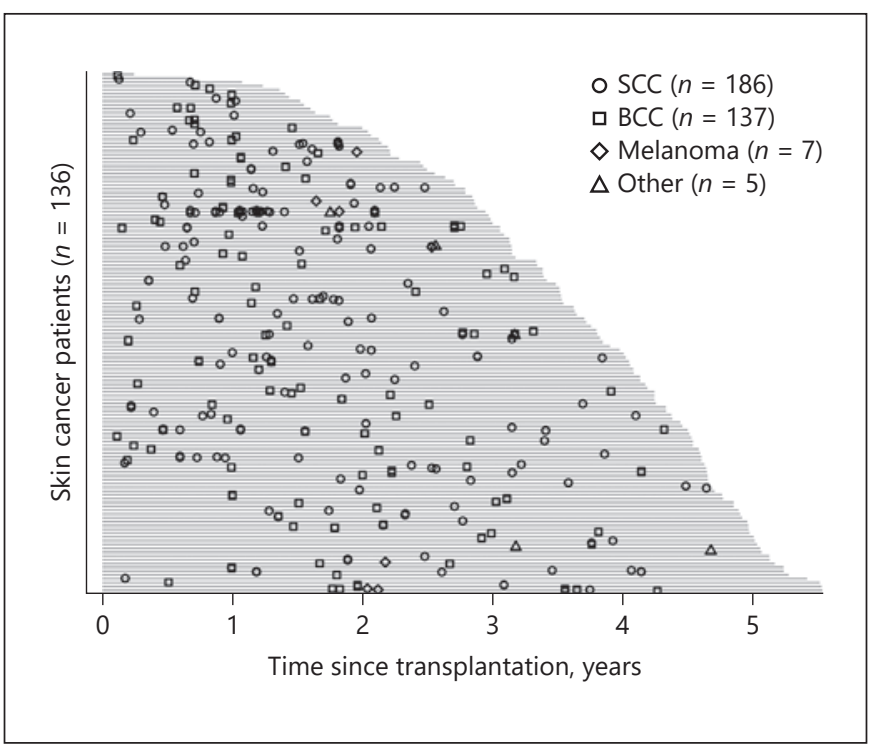

Fig. 3. Skin cancer events per patient after transplantation. Cases of skin cancer are displayed for squamous cell carcinoma (SCC) by open circles, basal cell carcinoma (BCC) by open squares, melanoma by open rhomboids and other cancers by open triangles over time. Grey bars represent the follow-up for each patient affected by skin cancer. "Other" includes dermal sarcoma, sarcoma not otherwise specified, sebaceous gland carcinoma, Kaposi sarcoma and atypical lymphocytic proliferation of T-cell type.

skin cancer overall (Table 4). For recurrent skin cancer, risk factors were age at transplantation, male sex, skin cancer before transplantation and also previous transplantation during the first 2 years after transplantation (Table 5). The number of immunosuppressive drugs was not significant for the development of recurrent skin cancer overall, neither in recurrent SCC nor BCC (Tables $6,7)$.

\section{Discussion and Conclusion}

Our study reports the skin cancer incidence after transplantation of solid organs within the STCS. Our demographic results are comparable with previous studies. The median age in our study was slightly higher than in other studies, where age ranged between 41 and 53 years at transplantation [19-22]. As in our study, most OTR included in studies from the USA, Australia, Sweden, Norway and Denmark were male [8, 19-24]. The majority of our patients received a kidney transplant, followed by liver transplantation. Compared with our data, most studies showed a higher proportion of kidney transplant recipients around 76\% [19-21]. Only one study from the USA showed a lower proportion of kidney transplant recipients of $48 \%$ [22]. Median follow-up and number of our enrolled patients were less than in similar studies, which included 5,27910,649 patients with a median follow-up from 4 to 8 years [19-22]. With an enrolment rate of $95 \%$ of transplant recipients in Switzerland, our study population largely resembles the ones reported in other countries and is highly representative of the transplant population in Switzerland [15].

Garrett et al. [22] showed an incidence rate of $8 \%$ for posttransplantation skin cancer in the USA. Australian kidney transplant recipients showed skin cancer inci- 
Fig. 4. a Number of skin cancers per patient. OTR, organ transplant recipients. The $y$ axis shows the number of patients in relation to the number of skin cancers on the $x$ axis. b Number of squamous cell carcinoma (SCC) per patient. The $y$ axis shows the number of patients in relation to the number of squamous cell carcinoma (SCC) on the $x$ axis. c Number of basal cell carcinoma (BCC) per patient. The $y$ axis shows the number of patients in relation to the number of basal cell carcinoma (BCC) on the $x$ axis.
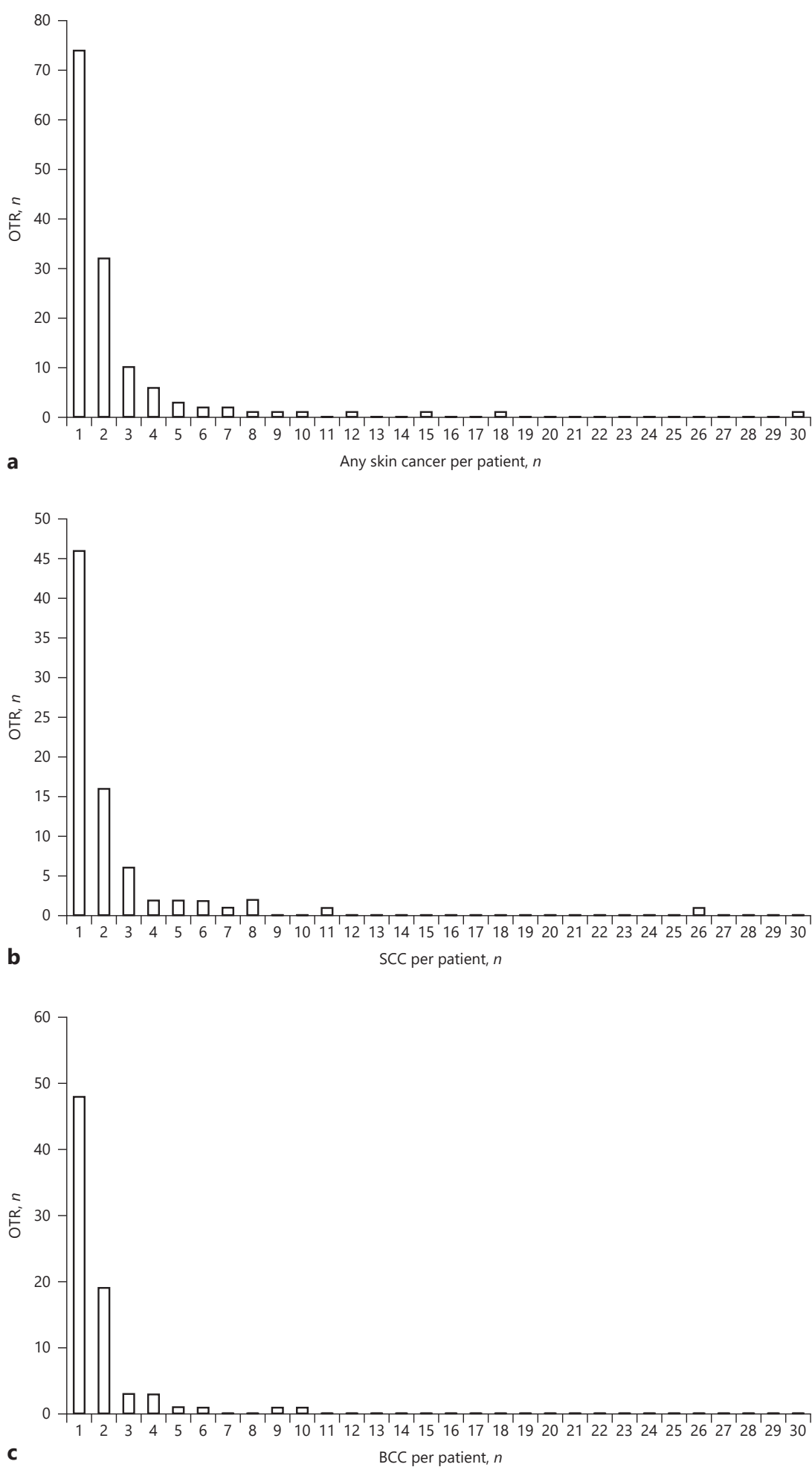

c BCC per patient, $n$ 
Table 6. Risk factors for recurrent SCC

\begin{tabular}{|c|c|c|c|}
\hline Risk factor & Reference & $\operatorname{HR}(95 \% \mathrm{CI})$ & $p$ value \\
\hline Age at transplantation ( $<2$ years of transplant) & - & $1.019(0.985-1.054)$ & 0.272 \\
\hline Age at transplantation ( $>2$ years of transplant) & - & $1.070(1.035-1.106)$ & $<0.001$ \\
\hline Male sex & female sex & $3.395(1.912-6.028)$ & $<0.001$ \\
\hline Previous skin cancer ( $<2$ years of transplant) & no previous skin cancer & $14.523(7.034-29.985)$ & $<0.001$ \\
\hline Previous skin cancer ( $>2$ years of transplant) & no previous skin cancer & $3.466(1.521-7.899)$ & 0.003 \\
\hline Previous transplantation ( $<2$ years of transplant $)$ & no previous transplantation & $3.747(2.08-6.751)$ & $<0.001$ \\
\hline Previous transplantation ( $>2$ years of transplant) & no previous transplantation & $2.027(0.962-4.271)$ & 0.063 \\
\hline Number of immunosuppressive drugs & - & $1.174(0.684-2.012)$ & 0.561 \\
\hline
\end{tabular}

The risk factors for recurrent squamous cell carcinoma (SCC) were calculated using multivariate analysis. -, lack of reference; HR, hazard ratio; $95 \% \mathrm{CI}, 95 \%$ confidence interval.

Table 7. Risk factors for recurrent BCC

\begin{tabular}{|c|c|c|c|}
\hline Risk factor & Reference & HR (95\% CI) & $p$ value \\
\hline Age at transplantation ( $<2$ years of transplant) & - & $1.060(1.028-1.093)$ & $<0.001$ \\
\hline Age at transplantation ( $>2$ years of transplant) & - & $1.059(1.014-1.106)$ & 0.01 \\
\hline Male sex & female sex & $3.605(1.831-7.098)$ & $<0.001$ \\
\hline Previous skin cancer ( $<2$ years of transplant) & no previous skin cancer & $5.315(3.22-8.776)$ & $<0.001$ \\
\hline Previous skin cancer ( $>2$ years of transplant) & no previous skin cancer & $5.009(1.356-18.506)$ & 0.016 \\
\hline Previous transplantation ( $<2$ years of transplant $)$ & no previous transplantation & $1.437(0.895-2.308)$ & 0.133 \\
\hline Previous transplantation ( $>2$ years of transplant) & no previous transplantation & $1.399(0.42-4.66)$ & 0.584 \\
\hline Number of immunosuppressive drugs & - & $1.148(0.726-1.813)$ & 0.555 \\
\hline
\end{tabular}

The risk factors for recurrent basal cell carcinoma (BCC) were calculated using multivariate analysis. -, lack of reference; HR, hazard ratio; $95 \% \mathrm{CI}, 95 \%$ confidence interval.

dences of 7, 25 and 79\% after 1, 5 and 20 years of followup, respectively [8]. In Sweden the cumulative incidence of non-melanoma skin cancer (NMSC) after transplantation reached $6.7 \%$ after 10 years and $20.4 \%$ after 20 years of follow-up [25]. In an Italian registry-based study of kidney and heart transplant recipients, the cumulative incidence reached 5.8 and $10.8 \% 5$ and 10 years after transplantation, respectively [26]. A Swiss long-term study of lung transplant recipients from 1992 till 2010 showed a cumulative incidence of SCC of 16.7 and $59.9 \%$ for 5 and 15 years after transplantation, respectively [27]. Except for NMSC in Sweden and Italy, our cohort reports lower incidence rates. This might be due to the shorter followup in our study, as skin cancer incidence in OTR seems to increase with duration of immunosuppression $[8,9$, 28-30]. Our data show an increasing probability of incident skin cancer with time after transplantation, in particular for SCC (Fig. 2).

Skin Cancer in Solid Organ Transplant Recipients in Switzerland
Compared to our tumour data, several publications including only heart and/or renal transplant recipients showed a much higher SCC-to-BCC ratio ranging between 2 and 7:1 [6, 7, 28,31-34]. Studies including all solid transplant recipients from Israel and Denmark reported an SCC-to-BCC ratio of 1.9:1 [6] and 1:1, respectively [20], more in line with our data. Also studies from countries in southern Europe described lower SCC-toBCC ratios of 1.1:1 in kidney transplant recipients in Portugal [35], 1.1:1 in Italian heart and 2.6:1 in Italian kidney transplant recipients [26]. For the general population in Switzerland, only the Canton of Vaud reports numbers which show the SCC-to-BCC ratio at 1:2.5 in the period between 1976 and 1992 [3]. The ratio of SCC to BCC in our present study might result from a rather short followup where the impact of previous sun damage before transplantation is still relatively predominant, while we expect an increase in the SCC-to-BCC ratio with a longer follow- 
up. Since AZA is known to increase especially the risk for SCC [36], another explanation for the lower SCC-to-BCC ratio in our study might be the low percentage of patients in our cohort receiving AZA compared to other similar cohorts, where the majority of the patient had AZA as component of their maintenance immunosuppressive therapy [7, 31-33].

Previous data showed that risk factors for NMSC after transplantation are age at transplantation, male sex, history of pretransplantation skin cancer, type of transplanted organ, high sun exposure and fair skin type [8-10, 19, $22,26-28,33,37,38]$. Our study finds correspondingly age at transplantation, male sex, previous skin cancer and additionally previous transplantation as risk factors for first and recurrent skin cancer. The duration of immunosuppression correlates with the increased skin cancer risk after transplantation, while the type of immunosuppressive drug seems an important risk factor $[7,8,10,31,33$, 39]. Dantal et al. [40] demonstrated in 1998 that more kidney transplant recipients developed a malignant disorder on a normal-dose cyclosporine regimen compared to patients on a low-dose cyclosporine regimen. There were also more patients with multiple skin lesions in the normal-dose cyclosporine group [40]. A change in immunosuppressive regimen from calcineurin inhibitor to mTOR inhibitor induced fewer NMSC $[41,42]$. AZA increases UVA photosensitivity and subsequent photodamage, potentially leading to a higher skin cancer occurrence $[43,44]$. Like many other studies we could not find an association for individual drugs with skin cancer. We did, however, find that the number of any immunosuppressive drugs is associated with the risk for a first skin cancer after transplantation, but not for recurrent skin cancer after transplantation. Our limited follow-up is the most likely limiting factor in associating skin cancer risk with individual immunosuppressants, followed by the limitation of our cohort data to the dose prescribed, not the trough levels achieved in serum. Selection bias for prescribing an mTOR inhibitor in high-risk individuals might also contribute. We hope that with a longer followup time, our cohort study will yield data on the impact of individual immunosuppressants.

OTR with previous skin cancer showed a higher hazard ratio for skin cancer in the first 2 years after transplantation compared to the period beyond 2 years. We believe that these findings show the decreasing impact of preexistent conditions in the course after transplantation. Previous skin cancer as a static risk factor tends to lose impact over time. Immunosuppression as dynamically increasing risk factor, however, gains impact over time, both in time after transplantation and by accumulated immunosuppressant use.

Limitations of our study are the limited number of skin cancer cases and the limited follow-up time of 36 months compared to similar studies. There is no matched control population because NMSC is not captured in the national cancer registry in Switzerland. Skin type and sun exposure, as well as serum levels of immunosuppressive drugs, were not captured in the STCS, precluding analysis of these factors for risk association.

\section{Conclusion}

In summary, our study is highly representative of the Swiss transplant recipient population. Skin cancer increases following transplantation with an important impact on morbidity and is associated with risk factors in our national cohort. Further follow-up will allow more granular dissection, for example, of individual immunosuppressants and their impact on skin cancer formation, potentially allowing immunosuppressive treatment regimes tailored to individual skin cancer risks in our transplant recipients.

\section{Key Message}

The incidence of skin cancer after organ transplantation is increased. We found some important risk factors.

\section{Acknowledgement}

We thank all patients, doctors and nurses associated with the STCS.

\section{Statement of Ethics}

All patients included in our report agreed to inclusion into the STCS for further use of their medical and personal data. This research project was approved by the Ethics Committee of Zurich, Switzerland (KEK-ZH-Nr. 2014-0276).

\section{Disclosure Statement}

The authors have no conflicts of interest to declare. 


\section{Funding Sources}

This observational study was not financially supported by external funding sources. This study has been conducted in the framework of the STCS, supported by the Swiss National Science Foundation and the Swiss University Hospitals (G15) and transplant centres.

\section{Author Contributions}

N.A.S. was involved in concept, design, data collection, data analysis and interpretation, and writing of the article. G.F.L.H. contributed to concept, design, data analysis and interpretation, and writing of the article. S.S. performed data analysis and statistics. A.W.A., A.C., M.D., O.G., M.H., R.E.H., E.L., M.M. and M.N. contributed to data collection, interpretation and writing of the article.

\section{References}

1 Bulliard JL, Panizzon RG, Levi F. [Epidemiology of epithelial skin cancers]. Rev Med Suisse. 2009 Apr;5(200):882, 884-8.

2 Lomas A, Leonardi-Bee J, Bath-Hextall F. A systematic review of worldwide incidence of nonmelanoma skin cancer. Br J Dermatol. 2012 May; 166(5):1069-80.

3 Levi F, Franceschi S, Te VC, Randimbison L, La Vecchia C. Trends of skin cancer in the Canton of Vaud, 1976-92. Br J Cancer. 1995 Oct;72(4):1047-53.

4 Stewart B, Wild C. World Cancer Report. Lyon: International Agency for Research on Cancer; 2014.

5 Euvrard S, Kanitakis J, Claudy A. Skin cancers after organ transplantation. N Engl J Med. 2003 Apr;348(17):1681-91.

6 Buell JF, Hanaway MJ, Thomas M, Alloway RR, Woodle ES. Skin cancer following transplantation: the Israel Penn International Transplant Tumor Registry experience. Transplant Proc. 2005 Mar;37(2):962-3.

7 Ong CS, Keogh AM, Kossard S, Macdonald PS, Spratt PM. Skin cancer in Australian heart transplant recipients. J Am Acad Dermatol. 1999 Jan; 40(1):27-34.

8 Bouwes Bavinck JN, Hardie DR, Green A, Cutmore S, MacNaught A, O'Sullivan B, et al. The risk of skin cancer in renal transplant recipients in Queensland, Australia. A followup study. Transplantation. 1996 Mar;61(5): $715-21$.

9 Jensen P, Hansen S, Møller B, Leivestad T, Pfeffer P, Geiran O, et al. Skin cancer in kidney and heart transplant recipients and different long-term immunosuppressive therapy regimens. J Am Acad Dermatol. 1999 Feb; 40(2 Pt 1):177-86.

10 Lindelöf B, Sigurgeirsson B, Gäbel H, Stern RS. Incidence of skin cancer in 5356 patients following organ transplantation. Br J Dermatol. 2000 Sep;143(3):513-9.

11 Hartevelt MM, Bavinck JN, Kootte AM, Vermeer BJ, Vandenbroucke JP. Incidence of skin cancer after renal transplantation in The Netherlands. Transplantation. 1990 Mar; 49(3):506-9.

12 Hall EC, Pfeiffer RM, Segev DL, Engels EA. Cumulative incidence of cancer after solid organ transplantation. Cancer. 2013 Jun; 119(12):2300-8.

13 Vajdic CM, van Leeuwen MT. Cancer incidence and risk factors after solid organ trans-

Skin Cancer in Solid Organ Transplant Recipients in Switzerland plantation. Int J Cancer. 2009 Oct;125(8): 1747-54.

14 Koller MT, van Delden C, Müller NJ, Baumann P, Lovis C, Marti HP, et al. Design and methodology of the Swiss Transplant Cohort Study (STCS): a comprehensive prospective nationwide long-term follow-up cohort. Eur J Epidemiol. 2013 Apr;28(4):347-55.

15 Berger C, Bochud PY, Boggian K, Cusini A, Egli A, Garzoni C, et al.; Transplant Infectious Diseases Working Group, Swiss Transplant Cohort Study. The swiss transplant cohort study: lessons from the first 6 years. Curr Infect Dis Rep. 2015 Jun;17(6):486.

16 Study ST. Swiss Transplant Cohort Study [Internet]Basel: University Hospital Basel; 2015. Available from: http://www.stcs.ch.

17 Grambsch PM, Therneau TM. Proportional hazards tests and diagnostics based on weighted residuals. Biometrika. 1994;81(3): 515-26.

18 Amorim LD, Cai J. Modelling recurrent events: a tutorial for analysis in epidemiology. Int J Epidemiol. 2015 Feb;44(1):324-33.

19 Krynitz B, Edgren G, Lindelöf B, Baecklund E, Brattström C, Wilczek $\mathrm{H}$, et al. Risk of skin cancer and other malignancies in kidney, liver, heart and lung transplant recipients 1970 to 2008-a Swedish population-based study. Int J Cancer. 2013 Mar;132(6):1429-38.

20 Jensen AO, Svaerke C, Farkas D, Pedersen L, Kragballe K, Sørensen HT. Skin cancer risk among solid organ recipients: a nationwide cohort study in Denmark. Acta Derm Venereol. 2010 Sep;90(5):474-9.

21 Rizvi SM, Aagnes B, Holdaas H, Gude E, Boberg KM, Bjørtuft Ø, et al. Long-term Change in the Risk of Skin Cancer After Organ Transplantation: A Population-Based Nationwide Cohort Study. JAMA Dermatol. 2017 Dec; 153(12):1270-7.

22 Garrett GL, Lowenstein SE, Singer JP, He SY, Arron ST. Trends of skin cancer mortality after transplantation in the United States: 1987 to 2013. J Am Acad Dermatol. 2016 Jul;75(1): 106-12.

23 Iannacone MR, Sinnya S, Pandeya N, Isbel N, Campbell S, Fawcett J, et al.; STAR Study. Prevalence of Skin Cancer and Related Skin Tumors in High-Risk Kidney and Liver Transplant Recipients in Queensland, Australia. J Invest Dermatol. 2016 Jul;136(7): 1382-6.
24 De Rosa N, Paddon VL, Liu Z, Glanville AR, Parsi K. Nonmelanoma Skin Cancer Frequency and Risk Factors in Australian Heart and Lung Transplant Recipients. JAMA Dermatol. 2019 Jun;155(6):716-9.

25 Adami J, Gäbel H, Lindelöf B, Ekström K, Rydh B, Glimelius B, et al. Cancer risk following organ transplantation: a nationwide cohort study in Sweden. Br J Cancer. 2003 Oct; 89(7):1221-7.

26 Naldi L, Fortina AB, Lovati S, Barba A, Gotti E, Tessari G, et al. Risk of nonmelanoma skin cancer in Italian organ transplant recipients. A registry-based study. Transplantation. 2000 Nov;70(10):1479-84.

27 Gerber SR, Seifert B, Inci I, Serra AL, Kohler $\mathrm{M}$, Benden C, et al. Exposure to moxifloxacin and cytomegalovirus replication is associated with skin squamous cell carcinoma development in lung transplant recipients. J Eur Acad Dermatol Venereol. 2015 Dec;29(12):2451-7.

28 Keller B, Braathen LR, Marti HP, Hunger RE. Skin cancers in renal transplant recipients: a description of the renal transplant cohort in Bern. Swiss Med Wkly. 2010 Jul;140:w13036.

29 Carroll RP, Ramsay HM, Fryer AA, Hawley $\mathrm{CM}$, Nicol DL, Harden PN. Incidence and prediction of nonmelanoma skin cancer postrenal transplantation: a prospective study in Queensland, Australia. Am J Kidney Dis. 2003 Mar;41(3):676-83.

30 O'Reilly Zwald F, Brown M. Skin cancer in solid organ transplant recipients: advances in therapy and management: part I. Epidemiology of skin cancer in solid organ transplant recipients. J Am Acad Dermatol. 2011 Aug; 65(2):253-61.

31 Fortina AB, Piaserico S, Caforio AL, Abeni D, Alaibac M, Angelini A, et al. Immunosuppressive level and other risk factors for basal cell carcinoma and squamous cell carcinoma in heart transplant recipients. Arch Dermatol. 2004 Sep;140(9):1079-85.

32 Moloney FJ, Comber H, O'Lorcain P, O'Kelly P, Conlon PJ, Murphy GM. A populationbased study of skin cancer incidence and prevalence in renal transplant recipients. $\mathrm{Br} \mathrm{J}$ Dermatol. 2006 Mar;154(3):498-504.

33 Ramsay HM, Fryer AA, Reece S, Smith AG, Harden PN. Clinical risk factors associated with nonmelanoma skin cancer in renal transplant recipients. Am J Kidney Dis. 2000 Jul;36(1):167-76 
34 Ramsay HM, Fryer AA, Hawley CM, Smith AG, Harden PN. Non-melanoma skin cancer risk in the Queensland renal transplant population. Br J Dermatol. 2002 Nov; 147(5):9506.

35 Pinho A, Gouveia M, Cardoso JC, Xavier MM, Vieira R, Alves R. Non-melanoma skin cancer in Portuguese kidney transplant recipients - incidence and risk factors. An Bras Dermatol. 2016 Jul-Aug;91(4):455-62.

36 Jiyad Z, Olsen CM, Burke MT, Isbel NM, Green AC. Azathioprine and Risk of Skin Cancer in Organ Transplant Recipients: Systematic Review and Meta-Analysis. Am J Transplant. 2016 Dec;16(12):3490503.

37 Tessari G, Naldi L, Boschiero L, Nacchia F, Fior F, Forni A, et al. Incidence and clinical predictors of a subsequent nonmelanoma skin cancer in solid organ transplant recipi- ents with a first nonmelanoma skin cancer: a multicenter cohort study. Arch Dermatol. 2010 Mar; 146(3):294-9.

38 Molina BD, Leiro MG, Pulpón LA, Mirabet S, Yañez JF, Bonet LA, et al. Incidence and risk factors for nonmelanoma skin cancer after heart transplantation. Transplant Proc. 2010 Oct;42(8):3001-5.

39 Tessari G, Girolomoni G. Nonmelanoma skin cancer in solid organ transplant recipients: update on epidemiology, risk factors, and management. Dermatol Surg. 2012 Oct; 38(10):1622-30.

40 Dantal J, Hourmant M, Cantarovich D, Giral M, Blancho G, Dreno B, et al. Effect of long-term immunosuppression in kidneygraft recipients on cancer incidence: randomised comparison of two cyclosporin regimens. Lancet. 1998 Feb;351(9103):6238.
41 Campbell SB, Walker R, Tai SS, Jiang Q, Russ GR. Randomized controlled trial of sirolimus for renal transplant recipients at high risk for nonmelanoma skin cancer. Am J Transplant. 2012 May;12(5):1146-56.

42 Guba M, Graeb C, Jauch KW, Geissler EK Pro- and anti-cancer effects of immunosuppressive agents used in organ transplantation. Transplantation. 2004 Jun;77(12):1777-82.

43 O'Donovan P, Perrett CM, Zhang X, Montaner B, Xu YZ, Harwood CA, et al. Azathioprine and UVA light generate mutagenic oxidative DNA damage. Science. 2005 Sep; 309(5742):1871-4.

44 Hofbauer GF, Attard NR, Harwood CA, McGregor JM, Dziunycz P, Iotzova-Weiss G, et al. Reversal of UVA skin photosensitivity and DNA damage in kidney transplant recipients by replacing azathioprine. Am J Transplant. 2012 Jan;12(1):218-25. 